\title{
Overlapping chromosomal regions for fertility traits and production traits in the Danish Holstein population
}

\author{
J. K. Höglund, ${ }^{*} † \ddagger^{1}$ A. J. Buitenhuis, ${ }^{* 1,2}$ B. Guldbrandtsen, ${ }^{*}$ G. Su, ${ }^{*}$ B. Thomsen, ${ }^{*}$ and M. S. Lund \\ *Aarhus University, Faculty of Agricultural Sciences, Department of Genetics and Biotechnology, PO Box 50, 8830 Tjele, Denmark \\ †VikingGenetics, PO Box 64, S-532 21 Skara, Sweden \\ ¥Sveriges Lantbruksuniversitet, PO Box 7070, 75007 Uppsala, Sweden
}

\section{ABSTRACT}

Before implementing selection based on quantitative trait loci (QTL) for fertility, it is important to determine the existence of correlated effects between the fertility QTL and QTL with effects on production traits. When a QTL is detected for a trait that is a composite of subtraits, it is of interest to validate which of the subtraits are affected by the QTL. Phenotypic and marker data were collected from 34 grandsire families from the Danish Holstein population. First, the trait data for "fertility treatments" were separated into their underlying subtraits: uterine infections, antibiotics placed in the placenta, and abortions. In addition, retained placenta was selected for analysis because it is related to uterine infections. A genome scan was performed using 416 microsatellite markers for the fertility treatment subtraits and retained placenta, and an additional genome scan for milk production traits conditional on the QTL regions for the subtraits and retained placenta was conducted. Second, we selected 24 genomic regions harboring QTL for fertility traits from a previous study. A QTL scan for milk production traits conditional on the selected regions was conducted. We found that 16 selected genomic regions containing a QTL for fertility (including the fertility treatment subtraits and retained placenta) also harbored QTL for milk yield or milk composition traits. Furthermore, 12 QTL regions corresponding to 9 different fertility traits (including the fertility treatment subtraits) did not harbor a QTL for milk production or milk composition traits; that is, the region was specific for the fertility trait. The genome scan for the fertility treatment subtraits did not correspond to the QTL found for fertility treatments. No QTL were detected for the subtrait abortion, however genome scans for retained placenta revealed 4 different QTL.

Received December 11, 2008.

Accepted July 6, 2009.

${ }^{1}$ Contributed equally to this work.

${ }^{2}$ Corresponding author: bart.buitenhuis@agrsci.dk
Key words: quantitative trait locus, female fertility, milk production trait, cattle

\section{INTRODUCTION}

During the last decade, the fertility of dairy cows has declined while milk production has increased (Aamand et al., 2008). The decline in female fertility has forced farmers to perform additional inseminations and has resulted in greater veterinary costs, increased culling rates, and greater replacement costs for the farmer. An unfavorable genetic correlation between female fertility traits and milk production has been reported, ranging from about -0.2 to -0.5 , depending on the trait and population (Pryce et al., 1997; Dematawewa and Berger, 1998; Roxström et al., 2001).

Some authors (e.g., Campos et al., 1994) have reported nonzero genetic correlations between milk composition traits and female fertility-related traits, indicating that the genetic factors that have favored an increase in milk production may underlie, at least in part, the decline in female fertility. The antagonistic relationship between milk production traits and fertility traits makes simultaneous genetic improvement of both groups of traits more difficult. Molecular genetics tools could be used to facilitate selection of genetic determinants by identification of QTL. Then these QTL could be incorporated in a breeding scheme by marker-assisted selection (MAS), a process that can be particularly beneficial for traits with a low heritability, such as fertility traits (Dekkers, 2004).

Milk production traits have much greater heritability values than do fertility traits. The heritabilities for milk yield, protein, and fat are in the range of about 0.20 to 0.40 . Meanwhile, fertility trait heritability values fall in the range of 0.02 to 0.04 for the Danish Holstein population (Aamand et al., 2008).

Before implementing selection based on QTL information in a breeding scheme, it is important to confirm if direct selection for QTL that favor greater fertility is hampered by correlated effects between the fertility QTL and QTL that influence production traits. One 
approach would be to search the genome for regions with putative effects on fertility traits (Höglund et al., 2009) and then search only among those identified QTL regions for additional effects on other traits such as production traits. Conditioning the QTL search for additional traits to specific regions increases the power to detect QTL for other traits. Thus, when such an approach is adopted, multiple testing corrections only have to be done over a smaller set of null hypotheses instead of for the whole genome. Here, we used this approach to investigate the fertility QTL regions described by Höglund et al. (2009) as having production trait effects.

Höglund et al. (2009) analyzed 12 fertility traits measured in the Danish and Swedish Holstein population. A scan of the Danish population of dairy cows for fertility treatments (FRT) revealed several QTL. The FRT trait, however, is composed of several subtraits, each of which could affect reproductive efficiency. These subtraits were divided into 3 groups: infectious reproductive disorders, other reproductive disorders, and hormonal reproductive disorders. It is unknown which of these subtraits describe the QTL found for FRT. Therefore, the trait FRT was decomposed into its underlying subtraits: uterine infection, antibiotics placed in the placenta (endometritis and metritis), and spontaneous abortions. In addition, the genome was also scanned for retained placenta (RP). Retained placenta can lead to the development of endometritis and metritis, which can impair the reproductive performance of the cow (LeBlanc, 2008). Retained placenta is therefore related to the trait FRT, as endometritis and metritis are part of FRT.

In this study, we performed a genome scan to identify QTL for FRT subtraits, abortion, and RP in the Danish Holstein population. Genomic regions previously identified as harboring QTL for fertility traits (Höglund et al., 2009) and the genomic regions identified in this study were then scanned for QTL for milk yield and milk composition traits.

\section{MATERIALS AND METHODS}

\section{Danish Holstein Population}

Marker and phenotypic data were collected from the Danish Holstein-Friesian population according to a granddaughter design (Weller et al., 1990). The population consisted of 34 grandsire families. The number of sons tested per grandsire ranged from 16 to 105 with an average of 55 sons per grandsire family. In total, 1,888 sons were genotyped. Bos taurus autosomes (BTA)1, BTA3, BTA5, BTA7, BTA8 to BTA11, BTA15, BTA16, BTA18, BTA21, BTA23, BTA26, and BTA29 were typed for all 34 families. Chromosomes BTA2, BTA4, BTA6, BTA14, BTA19, BTA20, BTA22, BTA24, and BTA25 were typed for 19 families, and BTA17 was typed for 20 families.

\section{Phenotypic Data}

Fertility Treatments. Fertility treatments were previously analyzed by Höglund et al. (2009). Because of differences between the Danish and Swedish recording systems regarding fertility treatments $\left(\mathbf{F R T}^{\mathbf{1}}\right.$, FRT $^{2}$, and FRT $^{3}$, for first, second, and third lactation, respectively), only records from Denmark were used in this study (Höglund et al., 2009). In Denmark, fertility treatments are recorded by veterinarians and trained AI technicians. Fertility treatment records include data describing hormonal reproductive disorders, infective reproductive disorders (including uterine infection and antibiotics placed in the placenta and other reproductive disorders (including abortion). The unit of measurement was treated or not treated ( 1 or 0 ) for any of the recorded diseases. Single-trait breeding value (STBV) for fertility treatments was predicted separately for first, second and third lactation, using the total number of individual records within lactation. For a detailed overview of the phenotypes recorded and models used in breeding value prediction, see http://www. nordicebv.info/Routine+evaluation/Fertility+traits/ Fertility+traits.htm.

Decomposed Fertility Treatments. The STBV for the subtraits included in FRT were calculated across lactations because the frequency of the underlying traits was too small to have reliable EBV for the individual lactations. The 3 main components of FRT were infective reproductive disorders, other reproductive disorders, and hormonal reproductive disorders.

Infective Reproductive Disorders. Uterine infection and antibiotics placed in the placenta are related and had a total frequency of $3.9 \%$. Uterine infection and antibiotics placed in the placenta combined (FRTA) was coded as a binary trait: if a cow had no uterine infection and no antibiotics placed in its placenta, the trait value for FRTA was 0; otherwise, the value of FRTA was 1 . The remaining diseases underlying infective reproductive disorders had a frequency less than $0.5 \%$ per lactation. No reliable breeding values could be calculated for these disorders.

Other Reproductive Disorders. Abortion had an overall frequency of $1.5 \%$ per recorded pregnancy. Two genetic components of abortion were studied: The direct abortion (DA) effect is the effect of a sire's genes acting through the genotype of the fetus and is measured as the abortion rate among pregnancies sired by a particular sire. The maternal abortion (MA) effect 
represents the effect of a sire's genes acting through the genotype of his impregnated daughters. It is measured as the abortion rate among pregnancies of heifers sired by the sire in question. Daughter group averages were calculated from the Danish Holstein-Friesian population. These daughter group averages were based on the abortion frequencies defined as the number of abortions divided by the total number of pregnancies (the sum of the numbers of calves born and abortions). The daughter group averages were calculated using annual calving data from January 1991 to December 2005.

Hormonal Reproductive Disorders. The frequency of cysts and cysts with hormone treatment was $0.68 \%$ and was therefore considered too small to predict breeding values reliably.

$\boldsymbol{R} \boldsymbol{P}$. Retained placenta was measured as a binary trait with a value 0 or 1 and occurred at a frequency of $7.8 \%$. The STBV for these traits were predicted using a single-trait repeatability linear sire model including year-month, herd-year, calving-age, lactation, cow (permanent environment), sire, breed-proportion and heterozygosity, based on the data pooled over the first 3 lactations using the DMU package (Madsen and Jensen, 2007).

Production Traits. Production traits in the analysis were milk yield, protein yield, fat yield, fat percentage, and protein percentage. Phenotype recording and models used in breeding value prediction for fat and protein percentage were as described in Danish Cattle Federation (2006). Meanwhile, the phenotypes used for milk yield, protein yield, and fat yield were EBV calculated using a single-trait BLUP sire model, without consideration of family structure among sires and correlations among the traits.

Fertility Traits. The QTL regions focused on in this study were identified based on prior data (Höglund et al., 2009). The fertility traits were predicted separately for cows $\left({ }^{\mathbf{C}}\right)$ and heifers $\left({ }^{\mathbf{H}}\right)$ for number of inseminations per conception (or culling) $\left(\mathbf{A} \mathbf{I} \mathbf{S}^{\mathbf{C}}\right.$ and $\mathbf{A} \mathbf{I} \mathbf{S}^{\mathrm{H}}$ ), 56-d nonreturn rate $\left(\mathbf{N R R} \mathbf{R}^{\mathbf{C}}\right.$ and $\left.\mathbf{N R} \mathbf{R}^{\mathbf{H}}\right)$ and length in days of interval from first to last insemination $\left(\mathbf{I F L}^{\mathrm{C}}\right.$ and $\mathbf{I F L}^{\mathrm{H}}$ ). Length in days of the interval from calving to first insemination (ICF) is only defined for cows. Detailed information on these traits can be found in Höglund et al. (2009).

\section{Marker Data}

The total length of the bovine genome is $3,179 \mathrm{cM}$. The genome was screened using 416 microsatellite markers with an average marker spacing of $7.64 \mathrm{cM}$. All 29 autosomes were typed for an average of 14 markers. Höglund et al. (2009) gives a detailed description of the markers and sire families used for each chromosome.

\section{QTL Mapping Scheme}

A whole-genome scan was performed for abortion traits (DA and MA), FRTA, and RP. Genomic regions harboring a fertility associated QTL based on our prior study (Höglund et al., 2009) and the results of the genome scan for FRTA and RP were selected and scanned for production traits within the marker bracket given in our previous report (Höglund et al., 2009). A single marker analysis was performed in cases where a QTL peak was located at the end of the chromosome outside the region covered by microsatellite markers in the genome scan, or the QTL peak was located at the marker. In total, 27 regions in the cattle genome containing a QTL for a fertility trait or a fertility treatment trait were scanned (Table 1).

\section{QTL Analysis}

The traits were analyzed employing a linear regression mapping procedure adapted from Haley and Knott (1992). All QTL analyses were done using the GDQTL4 program (unpublished; source code available from the author, Bernt.Guldbrandtsen@agrsci.dk), which determined linkage phases of the markers in the grandsires based on the marker types of the sons. Marker allele frequencies were estimated using an expectationmaximization algorithm (Dempster et al., 1977). Segregation probabilities were calculated using all marker genotypes on the chromosome simultaneously, together with allele frequencies where segregation was ambiguous. Phenotypes were then regressed on the segregation probabilities. The following regression model was applied in analyses on both across and within families:

$$
Y_{i j}=\mu_{i}+b_{i}^{(p)} X_{i j}^{(p)}+e_{i j}^{(p)}
$$

where $Y_{i j}$ is the single-trait EBV of son $j$ of grandsire $i$; $\mu_{i}$ is the overall mean of grandsire family $i ; b_{i}^{(p)}$ is the regression coefficient within grandsire $i$ at position $p$; $X_{i j}^{(p)}$ is the probability that QTL allele 1 (using an arbitrary labeling of chromosomes) being transmitted from grandsire $i$ given all the informative markers of son $j$; and $e_{i j}{ }^{(p)}$ is the residual effect given QTL position $p$.

Test for Whole-Genome QTL Detection. Two types of tests were conducted: a joint test and withinfamily tests. For the joint test, an $F$-statistic was calculated for each trait-chromosome combination across those grandsire families where both marker genotypes and STBV were available. For the within-family tests, an $F$-statistic was calculated for each grandsire familychromosome-trait combination, where both marker genotypes and STBV were available. The significance threshold was determined for each test individually by 
Table 1. Quantitative trait loci scan for the production traits conditioned on the marker bracket harboring a QTL for a fertility trait ${ }^{1}$

\begin{tabular}{|c|c|c|c|c|c|c|c|c|}
\hline $\mathrm{BTA}^{2}$ & Trait $^{3}$ & Marker bracket ${ }^{4}$ & Position $^{5}$ & $\mathrm{Fat}^{6}$ & Fat $\%^{6}$ & Protein $^{6}$ & Protein $\%^{6}$ & Milk yield ${ }^{6}$ \\
\hline BTA1 & FRTA & BMS4017(3.8)-INRA049(7.8) & $\begin{array}{l}53.2 \\
\quad 1.97(0.041) ; 3\end{array}$ & - & - & - & - & - \\
\hline BTA1 & FRT $^{1}$ & BMS918(130.0)-BMS4043(142.2) & 132.6 & $1.51(0.047) ; 3$ & - & - & - & - \\
\hline BTA1 & ICF & BMS918-BMS4043 & 140.8 & $1.51(0.047) ; 3[1]$ & - & - & - & - \\
\hline BTA2 & $\mathrm{NRR}^{\mathrm{C}}$ & TGLA44(3.8) & 3.9 & - & - & - & - & - \\
\hline BTA4 & $\mathrm{IFL}^{\mathrm{C}}$ & BMS2646(43.0) & 43.2 & - & - & - & - & - \\
\hline BTA6 & $R P$ & BM4311(97.7)-BM2320(127.3) & $\begin{array}{l}109.9 \\
2.18(0.011) ; 2\end{array}$ & - & - & - & - & - \\
\hline BTA6 & FRTA & BM4311-BM2320 & $\begin{array}{l}119.0 \\
2.25(0.02) ; 2\end{array}$ & - & - & - & - & - \\
\hline BTA7 & $\mathrm{AIS}^{\mathrm{H}}$ & DIK2895(103.0)-MB057(116.6) & 111.6 & - & - & - & - & - \\
\hline BTA9 & $\mathrm{IFL}^{\mathrm{H}}$ & BMS2151(4.8) & 4.9 & - & - & - & - & - \\
\hline BTA9 & IFL $^{\mathrm{C}}$ & UWCA9(49.0)-DIK4912(51.8) & 50.0 & - & - & - & - & - \\
\hline BTA10 & $\mathrm{FRT}^{3}$ & CSSM $38(11.0)$ & 11.1 & $1.48(0.034): 3$ & _- & - & _- & _- \\
\hline BTA10 & IFL $^{\mathrm{C}}$ & BMS2641(87.5)-BMS614(100.0) & 90.8 & - & - & - & $1.98(0.029) ; 6[1]$ & \\
\hline BTA10 & $R P$ & BMS614(100.0)-BMS2614(109.3) & $\begin{array}{l}100.1 \\
\quad 1.84(0.013) ; 2\end{array}$ & - & - & - & $1.98(0.029) ; 6$ & - \\
\hline BTA11 & ICF & HUJV174(92.1)-TGLA436(105.2) & 92.5 & - & - & - & - & - \\
\hline BTA12 & $\mathrm{NRR}^{\mathrm{C}}$ & BM6108(15.1)-BM860(50.3) & 40.6 & - & - & - & - & - \\
\hline BTA13 & ICF & BL1071(80.9)-AGLA232(91.4) & 89.7 & - & - & - & - & - \\
\hline BTA14 & $\mathrm{FRT}^{3}$ & RM180(33.2) & 33.3 & $1.63(0.034) ; 2$ & $1.85(0.01) ; 3[1]$ & - & $2.03(0.001) ; 3[1]$ & - \\
\hline BTA15 & $\mathrm{FRT}^{3}$ & BMS820(98.0)-BMS927(104.9) & 98.3 & - & - & - & $1.71(0.003) ; 3[2]$ & $1.52(0.033): 3[1]$ \\
\hline BTA17 & $\mathrm{FRT}^{2}$ & BM1862(80.8)-BM1233(92.1) & 86.3 & $1.70(0.035) ; 4$ & - & - & - & $1.75(0.03) ; 1$ \\
\hline BTA18 & $R P$ & BM6507(78.8)-TGLA227(84.1) & $\begin{array}{l}83.3 \\
1.75(0.038) ; 2\end{array}$ & - & - & $1.46(0.043) ; 4$ & - & - \\
\hline BTA20 & $\mathrm{FRT}^{2}$ & BMS703(60.0)-BM5004(71.8) & 64.3 & $1.79(0.027) ; 2$ & $1.89(0.03) ; 1$ & - & 2.59 (0.001); 2 & - \\
\hline BTA22 & $\mathrm{NRR}^{\mathrm{H}}$ & BM1558(19.1)-BM3628(47.1) & 43.5 & - & - & - & - & - \\
\hline BTA22 & $R P$ & BM4102(82.9) & $\begin{array}{l}83.3 \\
1.96(0.047) ; 3\end{array}$ & - & - & - & - & - \\
\hline BTA22 & $\mathrm{FRT}^{1}$ & BM4102 & 82.9 & - & - & - & - & - \\
\hline BTA24 & $\mathrm{AIS}^{\mathrm{C}}$ & BMS917(6.2) & 6.2 & - & $2.20(0.018) ; 3[1]$ & $1.65(0.044) ; 1[1]$ & - & - \\
\hline BTA24 & ICF & ILSTS065(27.3)-BMS1862(35.5) & 30.4 & - & $3.16(0.004) ; 6[2]$ & - & - & - \\
\hline BTA25 & $\mathrm{NRR}^{\mathrm{H}}$ & ILSTS102(7.2)-BMS2843(22.6) & 17.3 & - & - & - & - & - \\
\hline BTA26 & FRT $^{1}$ & BMS332(22.8)-RM026(37.6) & 31.7 & $1.53(0.035) ; 6$ & $1.52(0.024) ; 2$ & $1.56(0.029) ; 4$ & - & $1.78(0.002) ; 5$ \\
\hline BTA26 & $\mathrm{NRR}^{\mathrm{H}}$ & RME40(43.2)-IDVGA-59(53.5) & 45.7 & $1.54(0.034) ; 6$ & $1.82(0.003) ; 7$ & $1.62(0.028) ; 4$ & - & $1.95(0.002) ; 6$ \\
\hline BTA26 & IFL $^{\mathrm{C}}$ & BMS882(53.0)-BM804(60.5) & 53.7 & $1.54(0.034) ; 6[2]$ & $1.82(0.003) ; 7[2]$ & $1.62(0.028) ; 4[1]$ & - & $1.95(0.002) ; 6[2]$ \\
\hline
\end{tabular}

O

$\quad{ }^{2} \mathrm{BTA}=$ Bos taurus autosome.

${ }^{3}$ Traits: FRTA = combined trait of uterine infection and antibiotics placed in the placenta; $\mathrm{FRT}^{1}, \mathrm{FRT}^{2}$, FRT ${ }^{3}=$ fertility treatments in first, second, and third lactations, respec-
tively; ICF = length in days of the interval from calving to first insemination (cows only); NRR ${ }^{\mathrm{C}}$ and $\mathrm{NRR}^{\mathrm{H}}=56$-d nonreturn rate for cows and heifers, respectively; IFL ${ }^{\mathrm{C}}$ and IFL ${ }^{\mathrm{H}}$ $=$ length in days of interval from first to last insemination for cows and heifers, respectively; RP $=$ retained placenta; AIS $^{\mathrm{C}}$ and AIS ${ }^{\mathrm{H}}=$ number of inseminations per conception (or $^{\circ}$ culling) for cows and heifers, respectively; the fertility trait data were taken from Höglund et al. (2009). The results of the traits indicated in italics were generated in this study.

$\therefore \quad{ }^{4}$ Marker brackets with their positions in $\mathrm{cM}$ in parentheses.

$\stackrel{{ }^{6}}{6}$ Fertility trait position on the chromosome in cM. For the traits generated in this study, the $F$-statistic $(P$-value for the across-sire analysis in parentheses); and the number of sires $\stackrel{0}{N}$ segregating are indicated in italics. A sire was considered as segregating for a QTL if the $P$-value for the within-family analysis was $<0.05$.

Z $\quad{ }^{6}$ The $F$-statistic ( $P$-value for the across-sire analysis in parentheses); the number of sires segregating for the production trait QTL, and the number of overlapping sires between he fertility trait and milk production or composition trait (in square brackets). A sire was considered as segregating for a QTL if the $P$-value for the within-family analysis was $<0.05$. 
performing a permutation test with 1,000 permutations (Churchill and Doerge, 1994). A QTL was considered significant if it exceeded the $5 \%$ chromosome-wise threshold in the permutation distribution. For each QTL that was significant in the joint test, the number of grandsire families individually significant at a $5 \%$ level for a QTL on the same chromosome was counted.

Test for Specific Area QTL Detection. Similar tests were performed as for the whole-genome scan, but the significance threshold for each test was determined individually from the outcome of a permutation test with 1,000 permutations based on a smaller interval (Churchill and Doerge, 1994).

\section{RESULTS}

\section{Decomposed Fertility Treatments and RP}

The genome was scanned for FRTA and RP traits (Table 1). This scan revealed a QTL on BTA1 for FRTA at $53.2 \mathrm{cM}$. Within a region of $22 \mathrm{cM}$, QTL for RP $(116.2 \mathrm{cM})$ and FRTA $(119.0 \mathrm{cM})$ were detected on BTA6. On BTA10, a QTL was detected for RP located at $100.1 \mathrm{cM}$. On BTA18, a QTL for RP was detected at $83.3 \mathrm{cM}$. On BTA22, a QTL was detected for FRTA and RP at $83.3 \mathrm{cM}$. Only the QTL for the fertility subtraits on BTA22 coincided with the QTL for FRT ${ }^{1}$. The positions found on BTA1, BTA6, BTA10, and BTA18 did not coincide with the QTL detected for fertility treatments in an earlier study (Höglund et al., 2009).

\section{Abortion Traits}

The frequency of both DA and MA from 1999 to 2005 ranged from 1 to $2 \%$ in the Danish Holstein population. No QTL exceeding the 5\% chromosome-wise significance level were detected for either DA or MA in the Danish Holstein cattle population.

\section{Decomposed Fertility Treatments, RP, and Production Traits}

Screening the selected regions of the fertility treatments (Table 1) for QTL of production traits revealed 6 QTL regions for fat yield on BTA1, BTA10, BTA14, BTA17, BTA20, and BTA26, respectively. Three regions were detected for fat percentage, on BTA14, BTA20, and BTA26, respectively. For protein yield, 1 region was detected on BTA26. Four regions were detected for protein percentage on BTA10, BTA14, BTA15, and BTA20, respectively. Screening for milk yield revealed 3 regions, located on BTA15, BTA17, and BTA26, respectively.

\section{Fertility Traits and Production Traits}

The QTL regions for fertility traits were further scanned for fat yield, fat percentage, protein yield, protein percentage, and milk yield (Table 1 ). This scan revealed 2 significant regions for fat yield on BTA1 and BTA26. Three significant regions for fat percentage were detected: 1 region on BTA26 and 2 regions on BTA24. Two significant regions for protein yield were detected: 1 on BTA24 and 1 on BTA26. Two significant regions for protein percentage were detected on BTA9 and BTA10, respectively. A scan of the fertility QTL regions for milk yield revealed 1 region on BTA26.

\section{DISCUSSION}

For this study, we selected 27 genomic regions harboring QTL for fertility traits and screened them for different milk production traits. Screening small areas of the genome is advantageous because the maximum $F$-statistic in tests with permuted data occurs over a narrower range, leading to more liberal test thresholds.

\section{Decomposed Fertility Treatments and RP}

To understand the $\mathrm{FRT}^{1}$, $\mathrm{FRT}^{2}$, and $\mathrm{FRT}^{3}$ traits, 2 underlying components with the highest frequency (uterine infection and antibiotics placed in the placenta) were used to compose 1 combined trait over 3 lactations (FRTA). The advantage of combining the 3 lactations is that the frequencies of the fertility treatment indices are higher, which results in more reliable breeding values.

The frequencies for the groups "hormonal reproductive disorders" and "other reproductive disorders" were too small to predict breeding values reliably. However, the 2 QTL for FRTA did not overlap any of the QTL detected for FRT in our prior study (Höglund et al., 2009). Several factors could explain the lack of overlapping QTL. The QTL of the composite trait may have been caused by another subtrait that we could not test because of the unreliable breeding values. Alternatively, combining the 3 lactations as we did could have diluted the effects of the subtraits and prevented detection of a QTL. Finally, it could be that because of the low frequencies, the QTL for the composite trait is a false positive. Because of this uncertainty, we suggest using caution when interpreting the QTL for FRT.

Retained placenta is not used in the fertility treatments trait in the Danish breeding value estimation, but it can be considered as a pre-stage of uterine infection (LeBlanc, 2008). Quantitative trait loci for the trait RP 
were detected on 4 different chromosomes. The location of the RP QTL on BTA10 is only $10 \mathrm{cM}$ from $\mathrm{IFL}^{\mathrm{C}}$. This result is interesting given that the interval from first to last insemination is extended when problems arise after calving because of RP. Retained placenta is associated with the same marker (BM4102) as $\mathrm{FRT}^{1}$ on BTA22, even though RP is not a subtrait of FRT. Uterine infection-related trait is part of FRT. Further studies are necessary to validate whether the QTL found on BTA22 for RP is the same as the QTL for FRT ${ }^{1}$. Moreover, Thomasen et al. (2008) found a QTL for calf size in the adjacent chromosomal region. In the latter study, these authors found direct and maternal genetic components on calf size in adjacent marker brackets. We also previously found a QTL for NRR in the same adjacent region (Höglund et al., 2009). All of these findings were obtained within an approximately 40-cM segment. If confirmed by fine mapping, this could be of great advantage because these QTL could be used without conflicting with milk production traits in the Danish Holstein population.

Fertility treatment as a trait has also been measured in Sweden (Holmberg and Andersson-Eklund, 2006) and Finland (Schulman et al., 2008). However, the underlying treatments of the cows registered for the trait "fertility treatments" differed between the 2 Scandinavian countries (Johansson, 2007). This fact implies that even though the traits have the same name, they are not actually the same, which is supported by study results that showed no overlapping QTL between the Swedish and Finnish study (Holmberg and Andersson-Eklund, 2006; Schulman et al., 2008). Similarly, the Danish fertility trait QTL locations did not overlap with the Finish QTL locations (Schulman et al., 2008). However, the Swedish study found QTL for fertility treatments when co-factors were used in the QTL analysis (Holmberg and Andersson-Eklund, 2006), but only 1 QTL (BTA22) had an overlapping position with the Danish study.

\section{Abortion}

Because early abortions are difficult to detect, registration of abortions can be inaccurate. A cow could be registered as not pregnant while experiencing an early abortion. Hence, the reported frequency may be smaller than the true abortion frequency. The data obtained from the Danish Holstein cattle population had a small frequency of abortion and a low estimated heritability (0.075\%; G. Su; unpublished data). This small heritability value could explain, at least in part, why no QTL for abortion were detected in our study.

\section{Overlapping Regions for Fertility Trait QTL and Production Trait QTL}

Five regions showed evidence of QTL for more than 2 milk production traits. These regions were localized to BTA26, BTA20, and BTA14.

BTA26. On BTA26, 3 regions harboring QTL for $\mathrm{IFL}^{\mathrm{C}}, \mathrm{NRR}^{\mathrm{H}}$, and $\mathrm{FRT}^{1}$ were selected based on a prior study (Höglund et al., 2009). Scanning these regions for milk production traits revealed QTL for fat yield, fat percentage, protein percentage, and milk yield in all 3 regions. Prior QTL studies have also found milk production traits segregating on BTA26 for different breeds (http://genomes.sapac.edu.au/bovineqtl/home. php). However, most of the QTL found in other studies are not located at the same position as the QTL in our study. The overlapping regions of the fertility traits are within a 25-cM interval on BTA26. In another study based on the same animal material, it was shown that BTA26 also harbored a QTL for clinical mastitis in the same region (Lund et al., 2008). This convergence of findings implicates BTA26 as a prime candidate for further fine mapping.

BTA20. A QTL for $\mathrm{FRT}^{2}$ was detected on BTA20. We also detected QTL for fat yield, fat percentage, and protein percentage in this region. These findings are in agreement with studies showing QTL for milk yield and fat yield in the same region (http://genomes.sapac.edu. $\mathrm{au} /$ bovineqtl/home.php). However, a QTL for protein percentage had not previously been detected in this region.

BTA14. A QTL for $\mathrm{FRT}^{3}$ was detected on BTA14. We detected QTL effects on fat yield, fat percentage, and protein percentage in this region. Although the diacylglycerol O-acyltransferase (DGAT1) gene is not close, these fat and protein effects on BTA14 could be due to a DGAT1 gene effect. Many studies have shown milk or milk composition traits effects on BTA14 (http://genomes.sapac.edu.au/bovineqtl/home.php).

A QTL for protein percentage has also been described in the US cattle population (Schnabel et al., 2005). Different markers were used in the US study, but a comparison of the bovine map location of these markers suggests that the QTL position is near the region we detected. A scan of the Finnish Ayrshire breed for milk production QTL also revealed QTL for fat yield, fat percentage, and protein percentage in this region (Viitala et al., 2003). Although different markers were used, a comparison of the marker positions based on the bovine map showed that the QTL positions reported by Viitala et al. (2003) were close to those detected in the present study. The regions with overlapping QTL 
for fertility traits and production traits influence both group of traits. Fine mapping of the areas with overlapping QTL could provide insight to whether the fertility QTL and milk production QTL are regulated by one gene or by linkage.

\section{Specific Regions for Fertility Trait QTL}

Another 12 regions for 9 different fertility traits were believed to be fertility-specific QTL because no QTL for milk production traits were detected in these areas. The traits (and respective regions) were $\mathrm{NRR}^{\mathrm{C}}$ (BTA2, BTA12), $\mathrm{NRR}^{\mathrm{H}}$ (BTA22, BTA25), IFL ${ }^{\mathrm{C}}$ (BTA4), IFL ${ }^{\mathrm{H}}$ (BTA9), AIS $^{\mathrm{H}}$ (BTA7), ICF ${ }^{\mathrm{C}}$ (BTA11, BTA13), RP/ FRTA (BTA6), $\mathrm{FRT}^{1}$ /RP (BTA22), and $\mathrm{FRT}^{1}$ (BTA1). The QTL in these regions specifically influence fertility without influencing milk production traits in the Danish Holstein population.

\section{The Use of QTL in Selection}

Using genomic information in a breeding setting could facilitate early selection of those animals with the best potential for breeding. However, understanding the influence of a specific region on different traits could be used to select better combinations of regions and improve traits of interest. The results of our study provide information that allows a partial separation of milk production and fertility traits. Overlapping QTL regions for fertility traits and production traits can be evaluated for use in breeding using dense SNP typing. The resulting data will provide more-detailed insights into the nature of the overlapping QTL. Any linked QTL can then be separated and implemented to improve fertility without affecting production characteristics.

\section{CONCLUSIONS}

In this study, we found 12 QTL regions with effects on 9 different fertility traits (including the fertility treatment subtraits) that did not harbor any QTL for milk production or milk composition traits. Hence, the fertility QTL appear specific to the fertility traits. An additional 16 selected genomic regions containing QTL for fertility (including the fertility treatment subtraits) also harbored QTL for milk production or milk composition traits. The trait "fertility treatments" was decomposed into its underlying components: infective reproductive disorders, other reproductive disorders, and hormonal reproductive disorders. The genome scan for the fertility treatment subtraits did not correspond with the QTL found for fertility treatments. No QTL were detected for the subtrait abortion. Scanning the genome for the trait retained placenta revealed 4 different QTL.

\section{ACKNOWLEDGMENTS}

We thank the Danish Cattle Federation for providing phenotypic data. This project was funded by FREM98 DJF: New technologies in farm animal breeding and grant no. 34016503 136: DNA based selection to improve disease resistance, fertility, calf survival and production in Danish dairy cattle from the Danish Directorate for Food, Fisheries and Agri Business grant no. 3401-04-00853 and the Swedish Farmers' Foundation for Agricultural Research with co-funding from Viking Genetics. Viking Genetics is also acknowledged for providing semen samples.

\section{REFERENCES}

Aamand, G. P., M. B. Almskou, A. Fogh, D. Boelling, U. S. Nielsen, and J. Pedersen. 2008. Årsstatistik Avl 2007-2008. Report no. 119 from Danish Agricultural Advisory Service. Dansk Kvæg, Århus, Denmark.

Campos, M. S., C. J. Wilcox, C. M. Becerril, and A. Diz. 1994. Genetic parameters for yield and reproductive traits of Holstein and Jersey cattle in Florida. J. Dairy Sci. 77:867-873.

Churchill, G. A., and R. W. Doerge. 1994. Empirical threshold values for quantitative trait mapping. Genetics 138:963-971.

Danish Cattle Federation. 2006. Principles of Danish Cattle Breeding. 8th ed. http://www.lr.dk/kvaeg/diverse/principles.pdf Accessed Nov. 22, 2008.

Dekkers, J. C. M. 2004. Commercial application of marker- and geneassisted selection in livestock: Strategies and lessons. J. Anim. Sci. 82(E. Suppl.):E313-E328.

Dematawewa, C. M. B., and P. J. Berger. 1998. Genetic and phenotypic parameters for 305-day yield, fertility, and survival in Holsteins. J. Dairy Sci. 81:2700-2709.

Dempster, A. P., N. M. Laird, and D. B. Rubin. 1977. Maximum likelihood from incomplete data via EM algorithm. J. R. Stat. Soc. B 39:1-38.

Haley, C. S., and S. A. Knott. 1992. A simple regression method for mapping quantitative trait loci in line crosses using flanking markers. Heredity 69:315-324.

Höglund, J. K., B. Guldbrandtsen, G. Su, B. Thomsen, and M. S. Lund. 2009. Genome scan detects quantitative trait loci affecting female fertility traits in Danish and Swedish Holstein cattle. J. Dairy Sci. 92:2136-2143.

Holmberg, M., and L. Andersson-Eklund. 2006. Quantitative trait loci affecting fertility and calving traits in Swedish dairy cattle. J. Dairy Sci. 89:3664-3671.

Johansson, K. 2007. http://www.nordicebv.info/NR/rdonlyres/ CB110DEA-B02F-4641-B7A3-9747342EF6E9/0/20070619Diso rdercodesingeneticevaluationofreproductivediseasesinNAV2.pdf Accessed Aug. 31, 2009.

LeBlanc, S. J. 2008. Postpartum uterine disease and dairy herd reproductive performance: A review. Vet. J. 176:102-114.

Lund, M. S., B. Guldbrandtsen, A. J. Buitenhuis, B. Thomsen, and C. Bendixen. 2008. Detection of quantitative trait loci in Danish Holstein cattle affecting clinical mastitis, somatic cell score, udder conformation traits, and assessment of associated effects on milk yield. J. Dairy Sci. 91:4028-4036.

Madsen, P., and J. Jensen. 2007. A User's Guide to DMU. Version 6, release 4.7, University of Aarhus, Faculty of Agricultural Sciences, Aarhus, Denmark. 
Pryce, J. E., R. F. Veerkamp, R. Thompson, W. G. Hill, and G. Simm. 1997. Genetic aspects of common health disorders and measures of fertility in Holstein Friesian dairy cattle. Anim. Sci. 65:353-360.

Roxström, A., E. Strandberg, B. Berglund, U. Emanuelson, and J. Philipsson. 2001. Genetic and environmental correlations among female fertility traits and milk production in different parities of Swedish red and white dairy cattle. Acta Agric. Scand. A 51:714.

Schnabel, R. D., T. S. Sonstegard, J. F. Taylor, and M. S. Ashwell. 2005. Whole-genome scan to detect QTL for milk production, conformation, fertility and functional traits in two US Holstein families. Anim. Genet. 36:408-416.

Schulman, N. F., G. Sahana, M. S. Lund, S. M. Viitala, and J. H. Vilkki. 2008. Quantitative trait loci for fertility traits in Finnish Ayrshire cattle. Genet. Sel. Evol. 40:195-214.
Thomasen, J. R., B. Guldbrandtsen, P. Sørensen, B. Thomsen, and M. S. Lund. 2008. Quantitative trait loci affecting calving traits in Danish Holstein cattle. J. Dairy Sci. 91:2098-2105.

Viitala, S. M. N. F. Schulman, D. J. de Koning, K. Elo, R. Kinos, A. Virta, J. Virta, A. Mäki-Tanila, and J. Vilkki. 2003. Quantitative trait loci affecting milk production traits in Finnish Ayrshire dairy cattle. J. Dairy Sci. 86:1828-1836.

Weller, J. I., Y. Kashi, and M. Soller. 1990. Power of daughter and granddaughter designs for determining linkage between marker loci and quantitative trait loci in dairy cattle. J. Dairy Sci. $73: 2525-2537$. 